\title{
Environmental risks of using antibiotics in the Baikal region of Russia
}

\author{
$S$ Timofeeva ${ }^{1, *}, E$ Panasenkova $^{1}, G$ Badienkova $^{1,2}$, and $I$ Shupletsova ${ }^{3}$ \\ ${ }^{1}$ Irkutsk National Research Technical University, 83 Lermontova St., Irkutsk, 664074, Russia \\ ${ }^{2}$ East-Siberian Institute of Medical and Environmental Research SB RAS, 3, 12A microdistrict, \\ Angarsk, 665827, Russia \\ ${ }^{3}$ Irkutsk Interregional Veterinary Laboratory, 4 Botkina st, Irkutsk, 664005 Russia
}

\begin{abstract}
The article addressed the problem of environmental risks for the population of the Baikal region. The authors analyzed the sources of antibiotic release into the environment of the Baikal region and made a predictive assessment of the risks to public health due to the consumption of meat and dairy products.
\end{abstract}

\section{Introduction}

Antibiotics are saving lives in today's dire pandemic. Each time they are used, they can contribute to the development and spread of antibiotic resistance. Antibiotic resistance can spread through humans, farm animals, and the environment.

Drugs used for human therapeutic purposes and veterinary drugs based on antibiotics, having fulfilled their therapeutic functions, are excreted from the human and animal body as a result of natural excretion [1-3] and are distributed in environmental objects, i.e. water and soil. As a rule, these substances transit through treatment facilities and pose potential environmental risks to the population.

Sources of antibiotic residues and their metabolites are livestock farms, feed factories, large-scale dairy farms, aquaculture, poultry farms, etc. Environmental pollution occurs through the direct discharge of animal waste containing partially metabolized drugs, surface runoff from the territory, the addition of manure containing trace amounts of drugs, as well as through the direct grazing of animals treated with drugs.

Studies by a number of authors [2,3] have proven the high content of veterinary pharmaceuticals in soil, ground and surface waters, in particular, such drugs as tetracyclines, sulfonamides, aminoglycosides, $\beta$-lactams, macrolides and others have been identified.

Another insufficiently studied source of antibiotic release into the environment is the uncontrolled release of unused drugs to household waste dumps, their accumulation in wastewater, where they enter with urine and feces, transit through treatment facilities, and are not removed during the treatment process.

Antibiotics can participate in the re-circulation in the system [4] "human - medical and medicinal waste in landfills and in sewage - surface water bodies and groundwater -

\footnotetext{
*Corresponding author: sstimofeeva@mail.ru
} 
irrigated agriculture when growing plant products for humans and animal feed - meat and dairy products - human" (fig.1). Accordingly, antibiotics pose a threat of chemical damage to the population; therefore, recently, there have appeared publications aimed at assessing and predicting risks for the population [5-9].

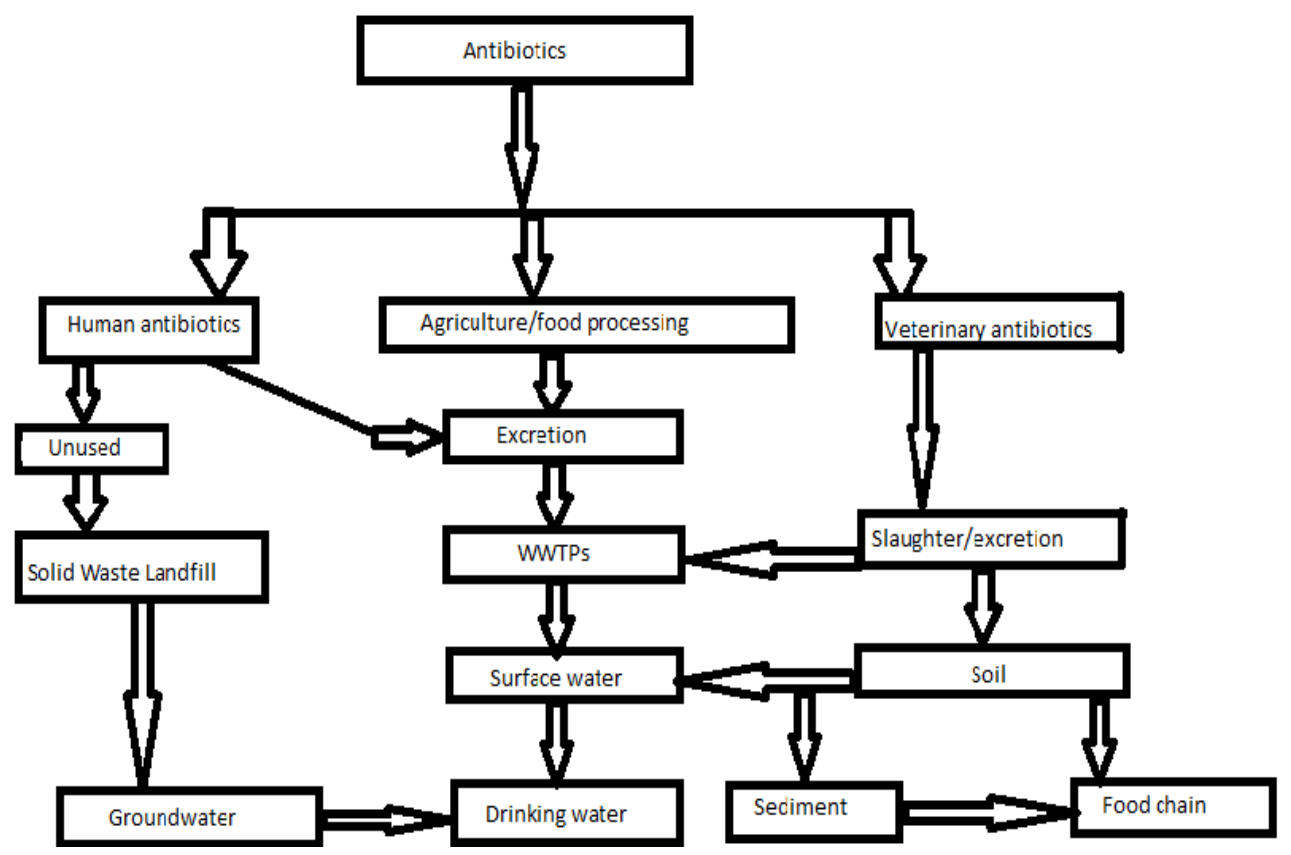

Fig. 1. Sources and pathways of occurrence of antibiotics in the environment.

The first studies of pharmaceutical waste in the environment appeared in the $60 \mathrm{~s}-70 \mathrm{~s}$ of the 20th century in England and Canada. Monitoring studies of micropollutants began in the middle of the $90 \mathrm{~s}$ thanks to the creation and implementation of highly sensitive, selective methods of chromatography-mass spectrometry, allowing them to be determined in ultra-small concentrations. Since the beginning of the 21 st century, pharmaceutical waste has been viewed as a new environmental problem requiring immediate solutions. This problem is especially acute in the Baikal natural territory, where targeted research has not yet been carried out, and there is very scattered information provided by the Irkutsk Interregional Veterinary Laboratory, which controls food products.

After analyzing the available scientific publications [1-14], it can be stated that the main sources of pharmaceutical waste are:

- livestock farms, feed factories, large-scale dairy farms, aquaculture, poultry farms, etc. Animal husbandry releases micropollutants into the environment through the direct discharge of animal waste containing partially metabolized drugs, surface runoff from the territory, the addition of manure containing trace amounts of drugs, as well as through the direct grazing of animals treated with drugs;

- sewage wastewater from water disposal systems of settlements and wastewater from hospitals;

- medicines from home first-aid kits remained unused after the completion of treatment, expired medicines purchased in excessive amount. After the expiration date, drugs are disposed of with household waste. Collection of unused medicines is not organized;

- growth in consumption of medicines;

- pharmaceutical waste from drug manufacturing enterprises. 
The aim of this work was to assess the sources of antibiotic release into the environment of the Baikal region and to make a predictive assessment of the risks to public health due to the consumption of meat and dairy products.

\section{Study Objects and Methods}

The objects of the study were meat and dairy products supplied to the markets and supermarkets of the Baikal region. The analysis of the antibiotic content was carried out by an accredited testing center (accreditation certificate No. ROSS RU.0001.21PO90) of the Irkutsk Interregional Veterinary Laboratory.

The selection of food samples for research is carried out in accordance with the requirements of GOST 7269-15 "Meat", GOST 31467-2012 "Poultry meat", GOST R 58340-2019 "Milk and milk products". Selected product samples were hermetically packed in polyethylene bags, labeled and numbered, and delivered to the laboratory for analysis. If necessary, they were stored at a temperature of $4 \pm 2{ }^{\circ} \mathrm{C}$ for a period not exceeding the shelf life of food products or frozen to a temperature of minus $10-12{ }^{\circ} \mathrm{C}$ and stored for no more than 2 weeks.

The QuEChERS method was used for sample preparation. It consists of two stages: extraction with a $1 \%$ solution of acetic acid in acetonitrile, and solid-phase extraction. A 10 g sample was placed in a $50 \mathrm{ml}$ test tube, $5 \mathrm{ml}$ of water was added and vigorously shaken for several minutes. Next, $10 \mathrm{ml}$ of a $1 \%$ solution of acetic acid in acetonitrile and QuEChERS extraction salts were added to the test tube and shaken again for 1 minute. After centrifugation ( $3 \mathrm{~min}$ ), an aliquot of the upper layer of acetonitrile was taken and HPLC-MS/MS analysis was performed on an EVOQ Qube liquid chromatography-mass spectrometer (State Register No. 56814-14).

\section{Results and Discussion}

The problem of contaminating livestock products with antibiotics is currently the subject of international discussion. In a number of European Union countries (Sweden, Denmark), the use of antibiotics is practically excluded in poultry farming. The United States, with their widespread concept of the mandatory use of antibiotics in animal husbandry to reduce the level of infection in animals and the risk of transmission of diseases to humans, criticize the position of EU that has banned feed antibiotics. China states that until the population of the country is provided with sufficient quantities of meat, it will use antibiotics in its production [1-9].

In the Russian Federation, feed and medicinal antibiotics are most often used in animal husbandry and veterinary medicine, such as grisin, bacitracin, groups of tetracyclines, penicillins, streptomycin and chloramphenicol. The content of other antibiotics is only monitored if there is information about their use. The technical regulations of the Customs Union TR CU 021/2011 and TR CU 034/20133, as well as SanPiN 2.3.2.2871-114, set the maximum allowable levels for 56 antibiotics, the values of which are consistent with the requirements of EU regulations. At the same time, in Russia, the standards for the content of tetracyclines in food products are kept at a more stringent level $(\leq 0.01 \mathrm{mg} / \mathrm{kg}$ in all standardized products) than the standards in the regulations of the Codex Alimentarius Commission (from $\leq 0.1$ to $\leq 1.2 \mathrm{mg} / \mathrm{kg}$ depending on the product) and EU (from $\leq 0.1$ to $\leq 0.6 \mathrm{mg} / \mathrm{kg})$.

Most often, antibiotics of the tetracycline group are used in animal husbandry to treat bronchopneumonia, dysentery, gastroenteritis, alimentary toxic dyspepsia, sepsis, infectious diseases of the urinary tract, coccidiosis, pullorosis, pasteurellosis and other diseases, and 
they are also used as growth stimulants in animals. Should the regime of prevention and treatment of animals be violated, or the waiting time before slaughter not observed, the remains of the tetracycline drugs can get into food products of animal origin.

Human consumption of products containing residual amounts of tetracyclines inhibits the intestinal microflora, can provoke dysbiosis, secondary fungal infections, manifestations of an allergic nature, cause nausea, vomiting, bowel dysfunction, changes in the mucous membranes of the gastrointestinal tract, reduces the body's resistance and increases the resistance of pathogenic microorganisms. Pregnant women, infants, persons suffering from liver and kidney diseases are especially sensitive to drugs of the tetracycline group. Consequently, the use of products with a high residual content of tetracyclines poses an environmental hazard to the population of the Baikal region.

In the Baikal region, sources of environmental pollution are livestock and poultry enterprises, farms. Among the large agricultural enterprises in the region are Usolye Pig Breeding Farm, Meget Poultry Farm, Sayansk Poultry Farm and others. Hormones and antibiotics are used when breeding animals and birds, and $75 \%$ of them are naturally excreted from animal organisms. Hormones are used in veterinary medicine and animal husbandry to stimulate the development of animals, improve fertility, accelerate puberty, regulate the timing of pregnancy, etc. Antibiotic residues are found in manure, plants grown in fields fertilized with manure, in soils, and groundwater. In the Baikal region, the entire mass of livestock waste is used as fertilizer in the fields, summer cottage gardens and, accordingly, is carried further along the ecological chain.

Table 1 presents the analysis of the regional structure of livestock farming in the Baikal region according to the 2016 census.

Table 1. Numbers of main types of livestock and poultry in the Baikal region as of June 1, 2016 (thousand heads) [15].

\begin{tabular}{|l|c|c|c|c|}
\hline Territory & $\begin{array}{c}\text { Farms of all } \\
\text { categories }\end{array}$ & $\begin{array}{c}\text { Agricultural } \\
\text { organizations }\end{array}$ & $\begin{array}{c}\text { Peasant (farming) } \\
\text { households and } \\
\text { individual } \\
\text { entrepreneurs }\end{array}$ & $\begin{array}{c}\text { Households } \\
\text { of the } \\
\text { population }\end{array}$ \\
\hline $\begin{array}{l}\text { Russian } \\
\text { Federation }\end{array}$ & 19342.0 & 8598.1 & 5566.2 & 2922.8 \\
\hline $\begin{array}{l}\text { Irkutsk } \\
\text { Region }\end{array}$ & 314.0 & 64.9 & 40.7 & 18.9 \\
\hline $\begin{array}{l}\text { Republic } \\
\text { of } \\
\text { Buryatia }\end{array}$ & 378.3 & 57.6 & 6.0 & 48.5 \\
\hline $\begin{array}{l}\text { Zabaikalye } \\
\text { Territory }\end{array}$ & 503.8 & 47.9 & 11.1 & 33.4 \\
\hline
\end{tabular}

Analysis of a large array of data showed the content of antibiotics in concentrations significantly exceeding the permissible ones in samples of meat and dairy product (Table 1).

Table 2. Identified samples of products containing antibiotics in concentrations exceeding the standard $(0.01 \mathrm{mg} / \mathrm{kg}$ for meat, zero for dairy products) according to the veterinary laboratory for 2017-2019.

\begin{tabular}{|c|c|c|}
\hline Test sample & $\begin{array}{c}\text { Number of samples with } \\
\text { tetracycline }\end{array}$ & $\begin{array}{c}\text { Number of samples with } \\
\text { penicillin }\end{array}$ \\
\hline Beef & 24 & 9 \\
\hline Pork & 18 & 6 \\
\hline Poultry & 14 & 4 \\
\hline
\end{tabular}




\begin{tabular}{|c|c|c|}
\hline Meat semi-finished products & 25 & 5 \\
\hline Cow's milk & 15 & 2 \\
\hline Dairy products & 18 & 3 \\
\hline Chicken egg & 9 & - \\
\hline Honey & 2 & - \\
\hline
\end{tabular}

The minimum and maximum value of antibiotics in meat and meat products ranges from 168 to 0.005 , and in milk and dairy products from 12 to $0.05 \mathrm{mg} / \mathrm{kg}$.

The environmental risks to a person consuming foods containing antibiotics can vary in a wide range and are assessed according to the methodology recommended by the US Environmental Protection Agency for assessing exposure upon oral consumption by the value of the hazard quotient [10].

According to the accepted classification, the risks according to the hazard quotient (HQ) are as follows: the level of risk is minimal, if $\mathrm{HQ}<0.1$; the level of risk is low, if $\mathrm{HQ}=0.1$ - 1.0; the level of risk is medium, if $\mathrm{HQ}=1.0-5.0$; the level of risk is high, if $\mathrm{HQ}=5.0$ 10.0 , and the level of risk is extremely high, if HQ $>10.0$. Table 2 shows the values of hazard quotients calculated for the standard consumption of meat and dairy products with the minimum and maximum concentrations of antibiotics

Table 2. Predicted value of the hazard quotient for the consumption of food contaminated with antibiotics.

\begin{tabular}{|c|c|c|}
\hline Test sample & $\begin{array}{c}\text { Predicted value of the hazard } \\
\text { quotient for the minimum } \\
\text { concentration }\end{array}$ & $\begin{array}{c}\text { Predicted value of the } \\
\text { hazard quotient for the } \\
\text { maximum concentration }\end{array}$ \\
\hline Beef & 0.9 & 5.2 \\
\hline Pork & 0.1 & 1.5 \\
\hline Poultry & 0.4 & 3.9 \\
\hline Meat semi-finished products & 0.8 & 4.5 \\
\hline Cow's milk & 1.1 & 3.8 \\
\hline Dairy products & 0.7 & 1.2 \\
\hline Table egg & 0.08 & 1.1 \\
\hline
\end{tabular}

The predictive assessment of environmental risks for the population based on the calculation of the hazard quotient has shown that the risks are classified as medium and low. The number of samples with the detected presence of antibiotics of the total amount examined is $0.2-2.5 \%$, which indicates the seriousness of the problem of environmental risks for the population of the Baikal region, and the necessity to continue research in the direction of the medical aspects of antibiotic resistance.

The work was supported by a grant from the Academic Council of INRTU.

\section{References}

1. S. Kurwadkar et al, Emerging Micro-Pollutants in the Environment: Occurrence, Fate, and Distribution ACS Symposium Series (American Chemical Society, Washington DC, 2015

2. S. Kurwadkar et al, J. Environ. Sci. 2(25), 268-273 (2013)

3. E. Archer et al, Chemosphere 174, 437-446 (2017)

4. A. Gosset et al, International Journal of Hygiene and Environmental Health 224, 11343 (2020)

5. N.V. Ivanova et al, Military medicine 16, 79-89 (2020) 
6. A. Amean, J of Global Pharma Technology 9(9), 58-64 (2017)

7. M.J. Benotti et al, Science of the Total Environment 622-623 (2018)

8. K. Oelkers, G. Floeter, Environmental Sciences Europe 31, 58 (2019)

9. C. Flma et al, Water 11(10), 2148 (2019)

10. T. Felicity, Public health panorama 3(1), 1-140 (2017)

11. A.N. Mukhutdinova, M.I. Rychkova, E.A. Tyumina, E.V. Vikhareva, Bulletin of Perm University 1, 65-76 (2015)

12. Yu.V. Akimenko, K.Sh. Kazeev, S.I. Kolesnikov, M.S. Mazanko, Proceedings of the Samara Scientific Center of the Russian Academy of Sciences 15, 3(4) (2013)

13. Regional Committee for Europe (2011)

14. Results of the All-Russian agricultural census, book 1 Livestock of farm animals (2016)

15. S. Timofeeva, G. Badienkova, XXI century Technosphere Safety 2(2), 57-67 (2017) 